\title{
Lessons Learned from Collapse of Zumrut Building under Gravity Loads
}

\author{
Can Balkaya*: \\ *Department of Civil Engineering, Faculty of Engineering and Architecture, Istanbul Gelisim University, Istanbul, Turkey \\ (cbalkaya@gelisim.edu.tr) \\ ¥Corresponding Author; Can Balkaya, Department of Civil Engineering, Istanbul Gelisim University, Istanbul, Turkey \\ Tel: +90 212422 7020, Fax: +90 212422 7401, cbalkaya @ gelisim.edu.tr
}

Received: 08.03.2017 Accepted: 05.06.2017

\begin{abstract}
The 11-story reinforced concrete Zumrut Building in Konya, Turkey collapsed on February 2, 2004. Ninety-two people died. This study was conducted to determine the mechanism of the collapse and identify lessons learned to avoid future disasters. Using structural drawings, material samples, and soil information obtained from the site, reasons for the collapse were investigated. A three-dimensional (3-D) structural model and analyses were performed using ETABSV8.11, and various possible critical cases were studied. The step-wise nonlinear analysis used to obtain the collapse mechanisms was an example of forensic structural engineering and revealed that the progressive collapse of the building was torsional, caused by decrease in structural system's capacity to redistribute gravity load after failure of a column. The lessons learned include the importance of project controls to reduce design and construction errors, ensure that construction and repairs are consistent with design intent, and changes are checked for safety and included in drawings. The importance of integrating architectural and structural systems to form 3-D continuous structural frames to reduce the probability of progressive collapse is also discussed.
\end{abstract}

Keywords Zumrut Building, Progressive collapse, Collapse mechanisms, 3-D finite element analysis, Failure of structure.

\section{Introduction}

Construction began on the Zumrut residential apartment building in 1994. The 11-story reinforced concrete building was located in the Selcuklu area of Konya, Turkey. At the time, the area was considered to be a "no seismic" zone, and structural designer calculations were performed considering gravity loads and wind forces only. The building survived just five years after the completion of construction. Progressive collapse of the building under gravity loads caused a sudden and total collapse on February 2, 2004 (Fig. 1), killing 92 people. The progressive collapse was started by a possible local failure in the ground-level columns. The first dynamic mode of the structure is the torsion mode. This causes a rotational/torsional motion and progressive collapse of columns in that story level and then progressive collapse of upper story levels results in total collapse of the building.

Most of Turkey lies within active earthquake regions, and building collapses, and damage due to earthquakes are fairly common. The damaged and collapsed buildings are typically restored or removed before evidence can be collected for a detailed investigation. But in the case of
Zumrut Building, a team of experts from Middle East Technical University (METU) was able to begin investigating the disaster during the removal of debris, after requesting the public prosecutor in Konya. The author was the head of the investigative team.

The investigation revealed that there were four main causes of the collapse of Zumrut Building [1]: 1) construction errors 2) project errors 3) lack of control of construction and projects and 4) different construction and repairs not shown in structural project.

A 3-D structural model of the building was developed to identify the possible progressive collapse mechanisms using the general structural analysis program ETABSV8.11 [3]. The 3-D modelling of Zumrut Building was then analysed using step-wise nonlinear analysis. When a structural element reached its capacity, it was crushed. Analysis of the structural systems continued until the collapse mechanisms of Zumrut Building were identified. After studying many possible critical paths, the progressive collapse was found to be a torsional rotation collapse. 

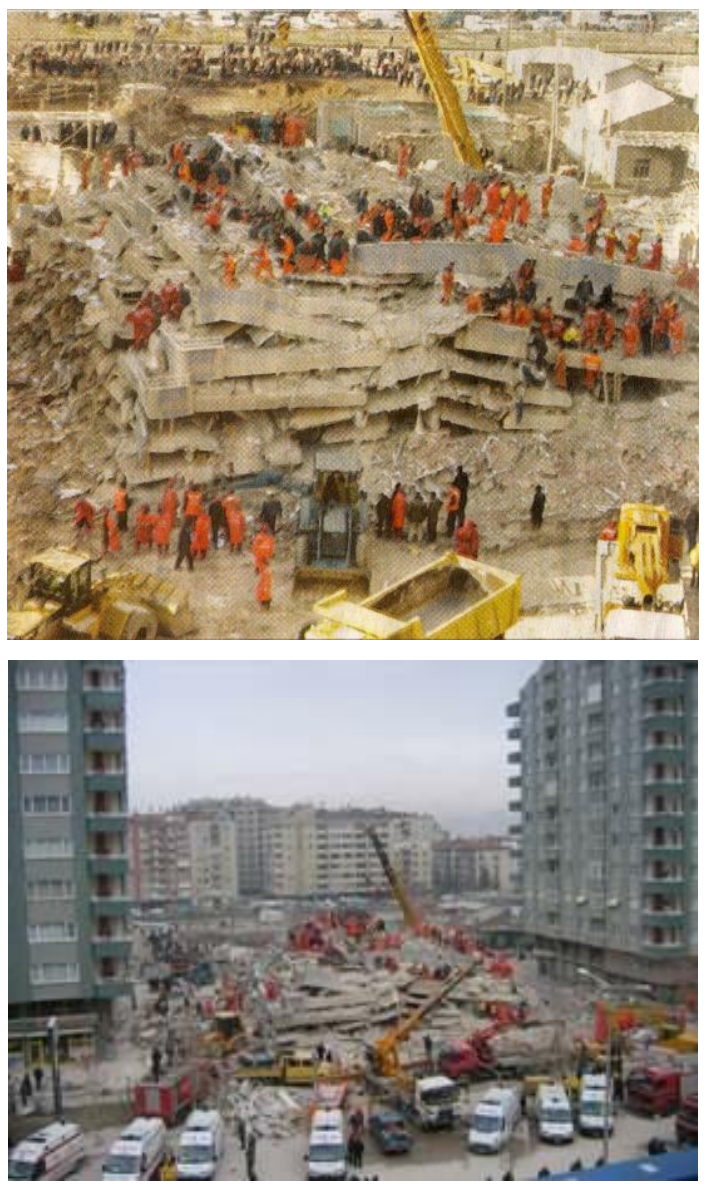

Fig. 1. Progressive collapse of Zumrut Building.

The lessons learned from this case emphasize the importance of appropriate structural systems, design approaches for gravity and lateral loads, and detailing in reinforced concrete buildings. They also emphasize the importance of control mechanisms during design and construction, construction quality and material quality, selection of a foundation system, and the effects of integrated architectural and structural systems in preventing progressive collapse.

\section{Investigation of Collapse Reasons of Zumrut Building}

\subsection{Construction Errors}

The sudden collapse of the 11-story reinforced concrete building was mainly due to poor construction and some design alterations that deviated from best practices for structural projects of this kind. The workmanship was not good. Concrete strength was lower than the project and code requirements for a reinforced concrete building. To determine the concrete quality used in the construction, many samples were taken on site after the collapse of the building. These samples were tested in the METU Department of Civil Engineering Material Lab, as shown in Fig. 2. The approved design compressive strength for the reinforced concrete was $160 \mathrm{kgf} / \mathrm{cm}^{2}$ (C14). Test results of concrete cylinders taken from the site revealed a compressive strength of $80 \mathrm{kgf} / \mathrm{cm}^{2}$ (C8). Since the samples were taken only from undamaged structural members, the compressive strength of damaged members is unknown.

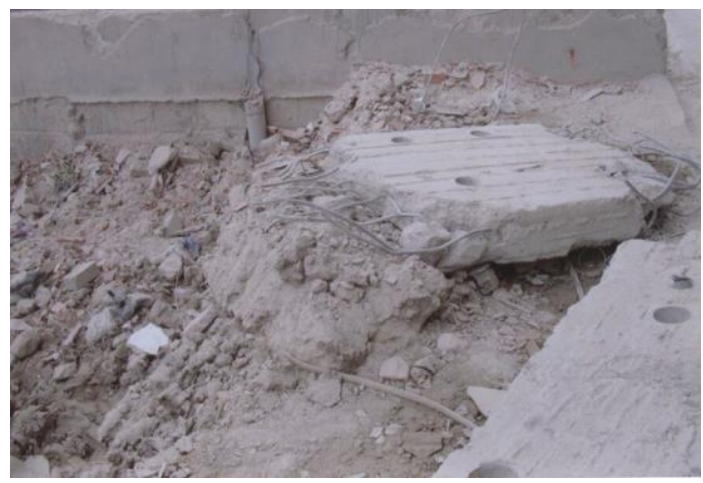

(a) Structural Element

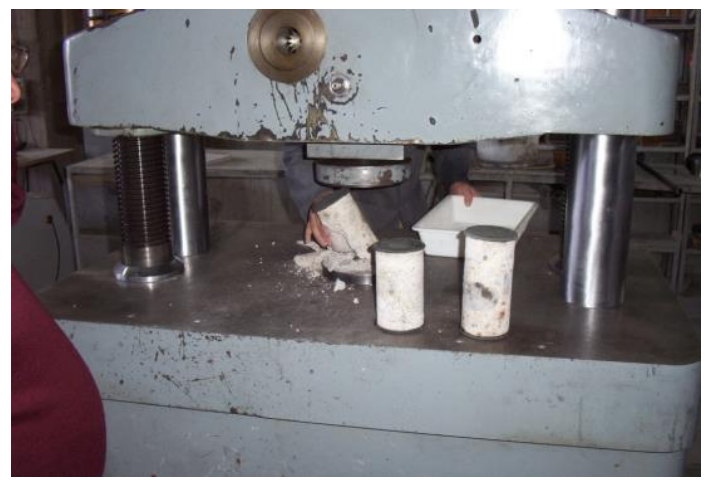

(b) Compressive Strength Test of Samples

Fig. 2. Concrete core samples.

Based on material testing and site investigation, it was observed that the concrete gradation in the Zumrut Building was not uniform. The gradation did not satisfy Turkish or ASTM Standards. The quantity of the sand present was more than that of the gravel. Some aggregates were very big, as shown in Fig. 3, which does not comply with standards. Sand and gravel were taken partly from a river and were probably unwashed.
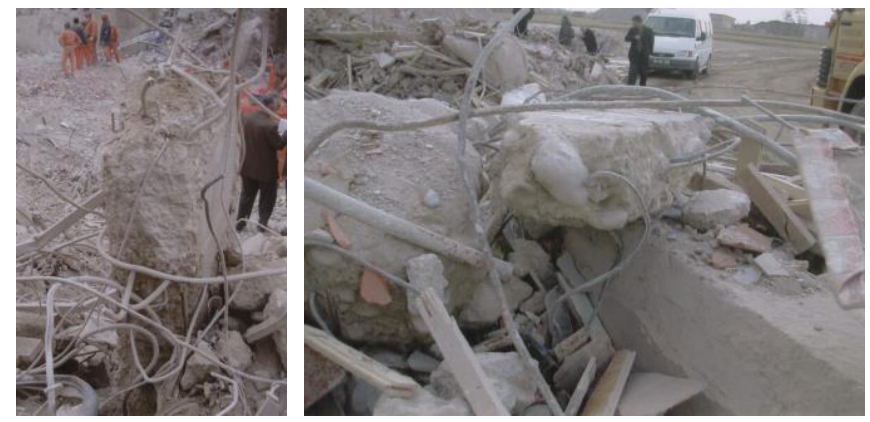

Fig. 3. Concrete gradation and cover.

Stirrup spacing, reinforcement cover, and replacements were also did not comply with code requirements. Small and large reinforcement material samples were taken from the site and tested in the METU Material Lab. Reinforcement types were found to be of the StI type $\left(2200 \mathrm{kgf} / \mathrm{cm}^{2}\right)$. Stirrups were not increased near the beam-column connection regions. In some locations, stirrup spacing was too large in some columns, as much as $40-50 \mathrm{~cm}$ with an average of $35 \mathrm{~cm}$.

Reinforcement cover varied significantly, it was found to be $5 \mathrm{~cm}$ in some columns. However, in some locations the 
reinforcements were replaced very close to the surface or inside the section (Fig. 3). On the other hand, the main longitudinal reinforcement of beams were replaced so closely that there was no enough space between the rebars for concrete. Beam dimensions in the approved structural design were $20 / 50 \mathrm{~cm}$. This small concrete beam sections, as well as use of reinforcement type StI $\left(2200 \mathrm{kgf} / \mathrm{cm}^{2}\right)$ instead of StIII $\left(4200 \mathrm{kgf} / \mathrm{cm}^{2}\right)$, resulted in a large amount of reinforcements in the beam design. In such cases, reinforcements must be replaced in layers rather than as a single bottom reinforcement layer (Fig. 4) in order to form bonding between concrete and reinforcement. On Zumrut Building, placement of the large amount of reinforcements as a single bottom layer resulted in no bond or a very weak bond of reinforcement in the concrete. Thus, most of the beams did not properly transfer the forces due to the lack of a strong bond during collapse of building.
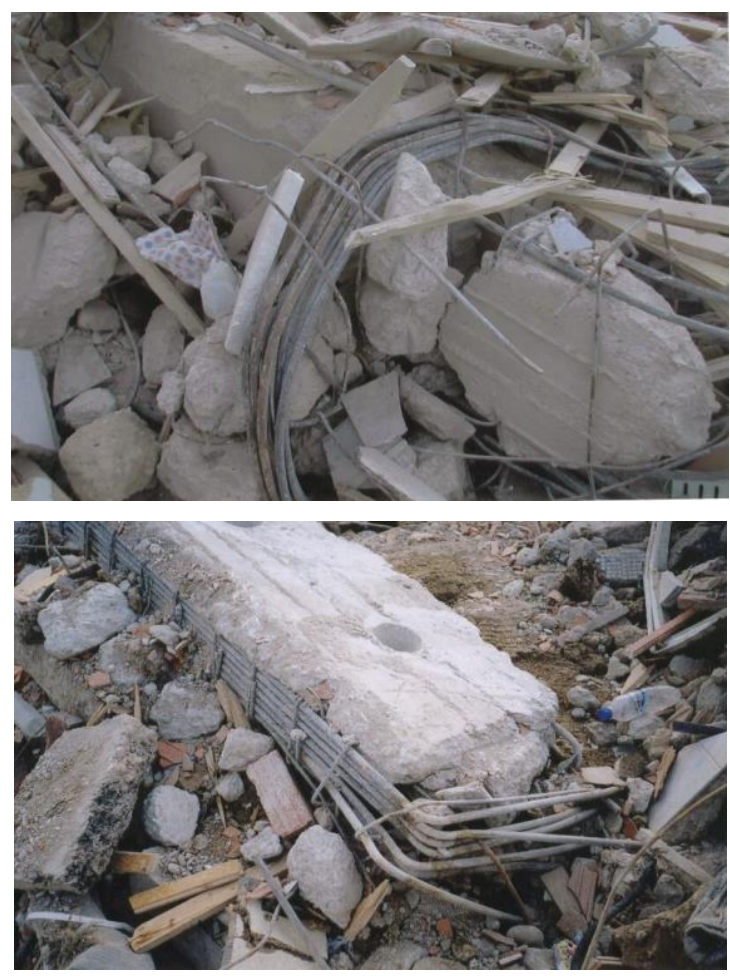

Fig. 4. Bond between concrete and reinforcement.

\subsection{Project Errors}

The Zumrut Building was modelled in 3-D using the analysis program ETABSV8.11 to check the existing structural project and design calculations. During the structural design calculation check, only the original project was considered; other repairs not shown in the structural drawings were not considered (repairs were only shown in architectural revised drawings). When the project was prepared, Konya was not considered as an earthquake region according to Turkish Earthquake Codes. For this reason, only vertical gravity loads (dead loads, live loads) and additional lateral loads (wind loads and their combinations) were considered in the design and control of the RC structural design calculations.

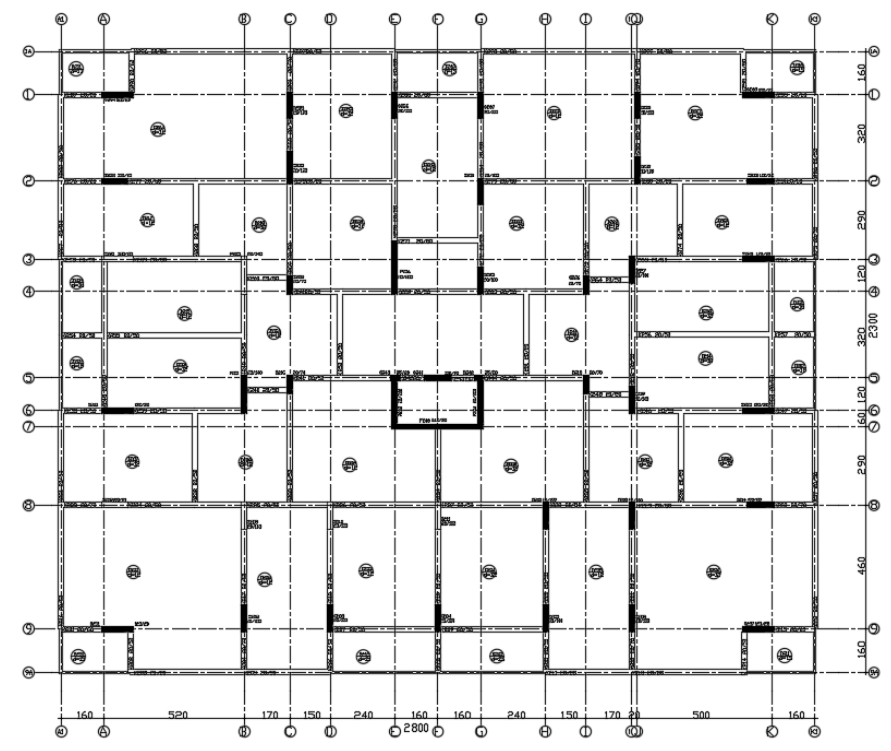

Fig. 5. Typical structural floor level of RC Zumrut Building.

The 11-story Zumrut Building was approximately $36 \mathrm{~m}$ high. The ground floor was $5.6 \mathrm{~m}$ high to accommodate shops, and the residential floors were $3 \mathrm{~m}$ high. Columns dimensions were generally $20 / 100 \mathrm{~cm}, 20 / 70 \mathrm{~cm}$, and $25 / 100$ $\mathrm{cm}(25 / 70 \mathrm{~cm}$ at the basement and ground floor levels). Beam dimensions were generally $20 / 50 \mathrm{~cm}$. Reinforced concrete slabs were $12 \mathrm{~cm}$. The rigidity center was at the right of the mid-part of the floor plan due to the shear walls of the elevator as shown in Fig.5.

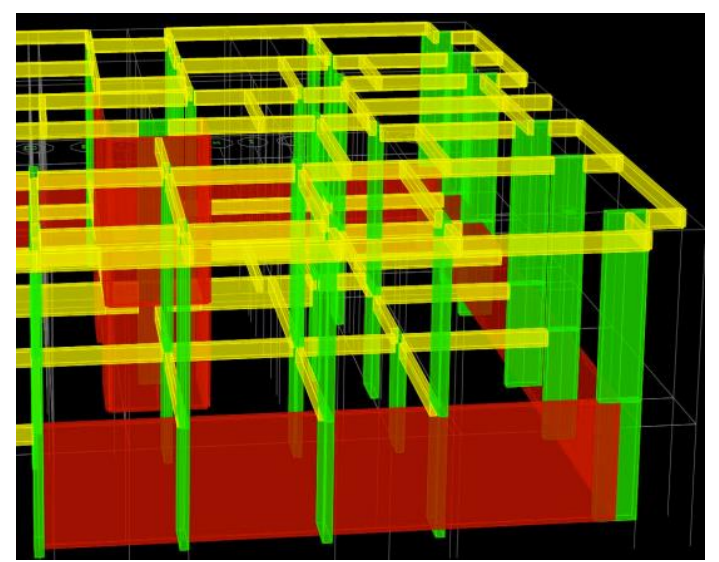

Fig. 6. Console part and beams located at out of frames at façade.

The floor areas were extended $1.5 \mathrm{~m}$ outside the frames all around the façade except at the ground level, as shown in Fig. 6. Between the columns around the exterior part of building, there are no beams. This may be due to architectural views as shown in Fig. 5 and Fig. 6. Thus, the frames were effectively not working, due to the lack of beams in the frame axes. The beams were connected to the frame columns using a cantilever beam and were located at the outer perimeter of the plan. This also resulted in the exterior frame column being subjected to large console load effects in the out-of-frame elevation. Corner columns were more critical. The outer parts of the building frames were working not effectively under lateral loads to transfer the loads when the stability of the building changed. Thus, the 
torsional resistance of the building was very low. On the other hand, there were discontinuities in the structural frame systems in both directions. Most of the frames, as shown in the structural plan (Fig. 5), were single-span frames especially in the short direction of the building. There was no direct connection between the frames; they were discontinuous in both directions. Some of them were not even located in the same line as that of the axes. There were four flats on each floor, but as seen in the floor plan in Fig. 5, the layout was not symmetric, and flats had different construction areas. When the author asked why the four flats were not symmetrically located in the floors, the reason was given as the consideration of the percentage sharing of the landowners. All columns between the $\mathrm{B}$ and $\mathrm{J}$ axes in the plan shown in Fig. 5 were located in the same direction as strong directions.

Existing reinforced concrete design calculations were checked. The calculations considered allowable stress design but included conceptual design errors. For example, the project designers used higher allowable concrete stresses for the concrete by considering the critical load case as the combination of gravity loads plus lateral wind forces (DL, LL, WL), which resulted in the selection of small column and beam dimensions. However, when considering the primary gravity loads, it was observed that this resulted in large structural sections in this load case. All combinations must be considered in structural design. In particular, basement and ground floor column dimensions must be 25 $45 \%$ larger than the project calculations.

As noted above, the structural frame system was discontinuous in both directions. The frame system in the basement and on the ground floor became all the more critical because of project errors and structural irregularities such as beams that were not located in the frame axes between the columns, reinforcement detailing mistakes, small column and beam sizes due to design calculation mistakes, and soft story irregularity due to the $5.6 \mathrm{~m}$ height of ground floor columns. Discontinuous frames were connected to other frames using primary and secondary beams. Maybe for architectural reasons, the beam dimensions were $20 / 50 \mathrm{~cm}$ for the console, and there was large frame spacing. Thus, these beams became more critical. Since the beam sections were small, more reinforcements were required and replaced in the beams with no or less bonding.

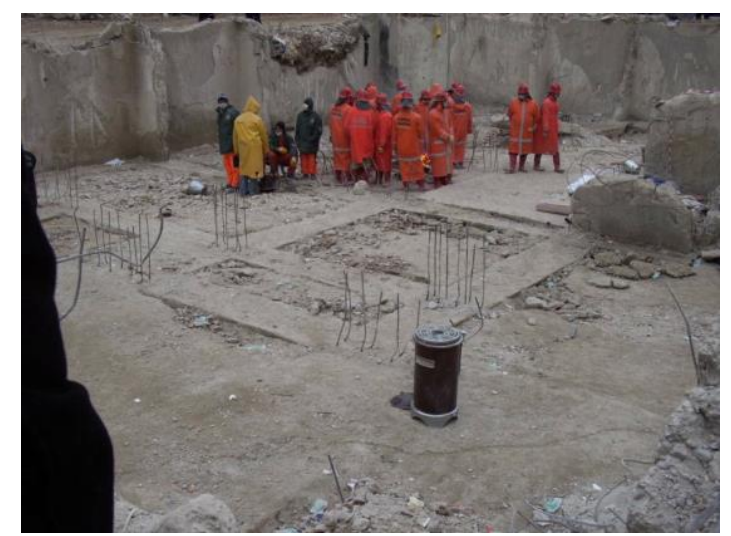

Fig. 7. Continuous foundation system in both directions.
The building foundation was a continuous foundation system in both directions, constructed in a grid system with shear walls around the perimeter of the basement (Fig. 7 and Fig.8). No damage was observed in the foundation after removal of the debris.

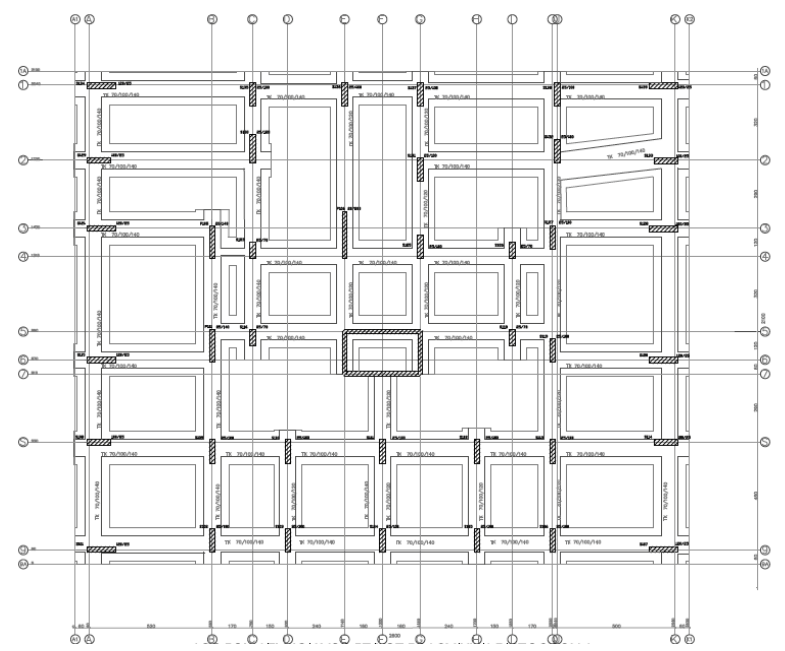

Fig. 8. Foundation plan.

Soil samples were taken during the site investigation (Fig. 9). The soil in the project site was silty clay, and no groundwater and settlement problems were observed after the collapse of the building. Thus, it was concluded that the soil and foundation system did not have any major effect on the collapse of Zumrut Building.
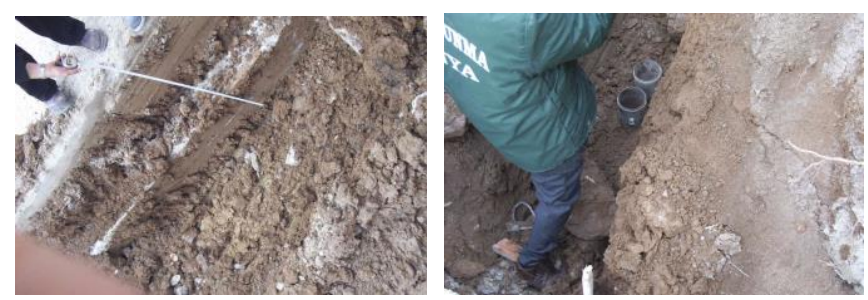

Fig. 9. Soil samples and foundation depth.

\subsection{Different Construction and Repairs without Checking Structural Safety}

Construction and repairs were not shown or different than structural projects. It was observed from the collapsed building that the ground floor level (of shops) and roof level were constructed as ribbed slabs of $32 \mathrm{~cm}$ rather than reinforced concrete slabs of $12 \mathrm{~cm}$, as shown in the approved structural drawings. The ribbed slabs were approximately two times heavier than the $12 \mathrm{~cm}$ of reinforced concrete slab. This substitution was not shown in the structural drawings, and structural calculations were not performed for ribbed slabs constructed at the two floors. In addition, two U80 steel profiles with lengths of $5 \mathrm{~m}$ were found at the right side of the back of the building. They may have been used under beams in the ground floor level because the ground floor was $5.6 \mathrm{~m}$ high (0.6 m beam depth). Approved architectural drawings showed an internal floor level of +3.00 with beams between the ground floor and first floor. But these alterations shown in the architectural drawings were not shown in the 
structural drawings as well as not checked for structural safety. During the removal of debris, a column of variable dimensions was also found at the ground floor (Fig. 10). The cross-section of the column size varied from $25 / 70 \mathrm{~cm}$ at the top to $25 / 40 \mathrm{~cm}$ at the bottom. This variation was probably to provide more spacing.

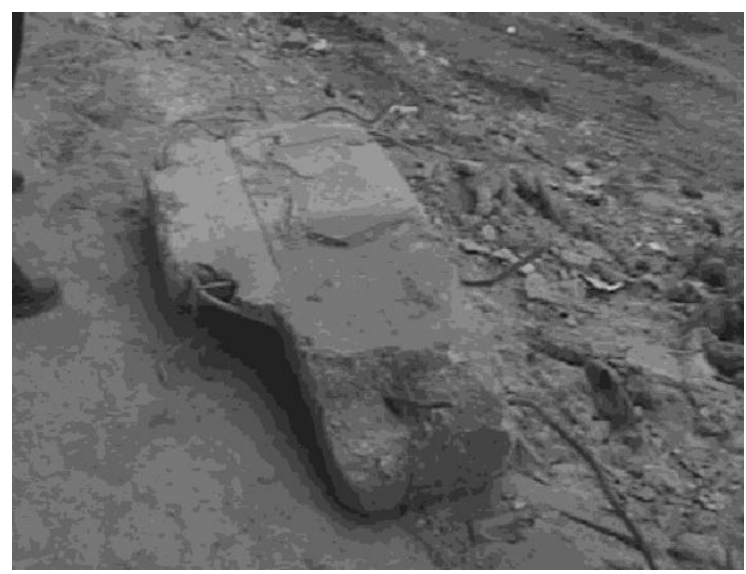

Fig. 10. Column found in debris with variable cross-section (Bottom part 25/40 cm, upper part 25/70 cm) at the ground level.

\subsection{Lack of Control of Construction and Projects}

Project and construction errors, and some construction and repairs those were not shown in the structural project drawings indicated that the supervision of construction and the control of the project were inadequate. Most probably, it was considered as a mere formality. Although a RC building with a height of $36 \mathrm{~m}$ can be considered as a low to medium high-rise building in Konya, the control mechanisms on these buildings require much more specific attention.

\section{3-D Nonlinear Finite Element Analysis and Collapse Mechanism}

3-D modelling of Zumrut Building (Fig. 11) was analysed using step-wise nonlinear analysis [2]. Column capacities were calculated by using material quality obtained from test results. When a structural element reached its capacity, it was crushed, and analysis continued until the collapse mechanism was determined. The progressive collapse of the building was a torsional collapse (Fig. 12). Possible local failure mechanisms would cause a progressive failure of the story columns due to excess capacity on neighbouring structural elements. This story collapse resulted in a torsional motion. To obtain the torsional motion evidenced by the original collapse of Zumrut Building, many alternative potential collapse paths for the columns were studied.

The study revealed that if a column was crushed, the neighbouring column faced additional loads of $20 \%$. Since most of the columns were near capacity-due to project and construction errors, and low-quality concrete-these additional loads caused progressive collapse of adjacent columns.
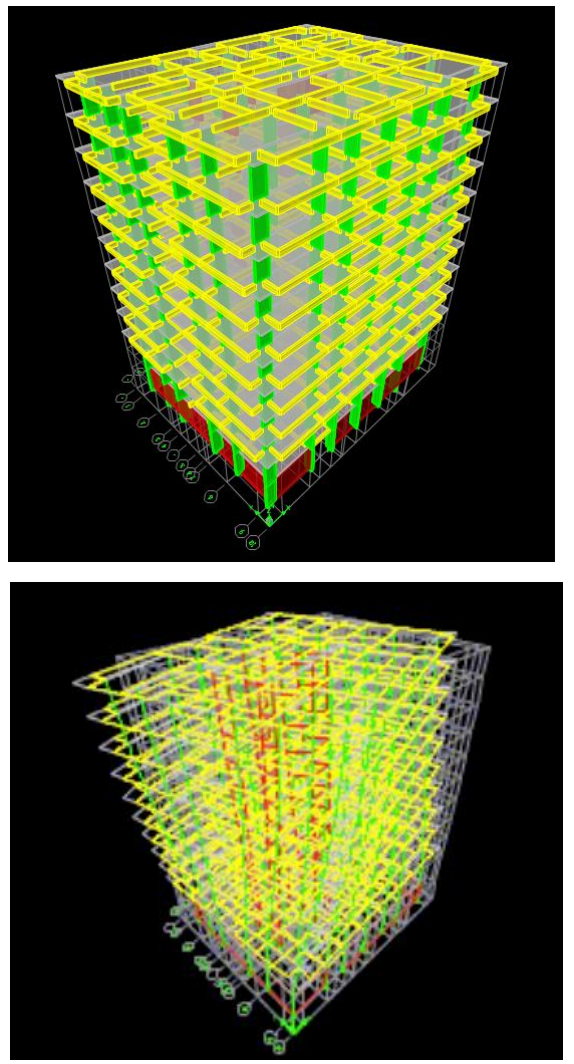

Fig. 11. 3-D finite elements modeling of RC Zumrut Building.
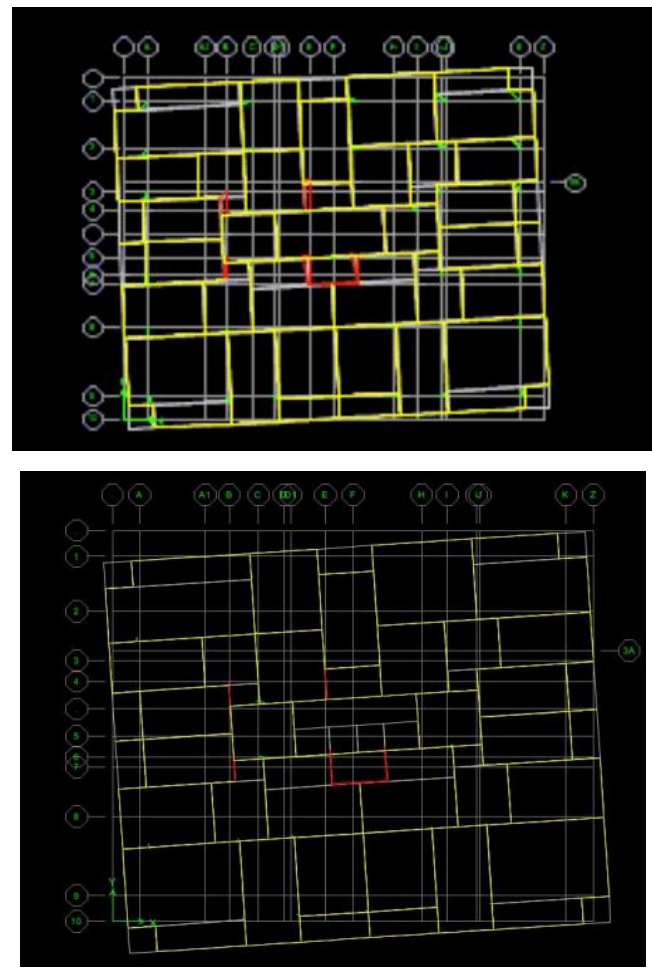

Fig. 12. Rotational/torsional collapse of Zumrut Building in plan view.

The building torsional capacity was very low, and structural frames were not continuous in both directions; discontinuities in the 3-D structural framing, and very low bonds in the RC beams, result in improperly redistribution of 
the forces. The result was collapse of story level, progressive collapse of the upper stories and total collapse of Zumrut Building.

Thus, progressive collapse of Zumrut Building occurred due to loss of gravity load capacity to redistribute the load after the failure of a column. This was caused by a lack of frame continuity, capacity, and other mechanisms. Removal or crushing of a single column from a building such as this would cause it to collapse. To obtain the original collapse torsional rotation, many critical load paths were applied to the model. Depending on the column that was removed or failed the torsional rotation direction and collapse angle and mechanism were different. Each column was removed alternately from each level, and then capacity checks and load distributions were done for the new situation. In this manner, the progressive collapses of each floor level were obtained. After considering many alternative cases, the reason for the collapse of Zumrut Building was obtained in the analysis. This was a forensic structural engineering study to investigate and determine the causes of structural failure by using 3-D nonlinear finite element analyses.

\section{Lessons Learned from Zumrut Building Collapse}

Unexpected loads may occur after construction of a high-rise building due to events such as terrorist attacks, gas explosions, blasts, fires, or accidental collisions (e.g., with a truck or plane). Repair and reduction of structural element capacity or an increase in the design loads due to new usage are also factors, as new façades that impose additional gravity loads. Increased seismic loads and wind forces may also arise. However, the Zumrut Building disaster occurred entirely under gravity loads. Zumrut Building in Konya, Turkey was collapse due to the combination of the following reasons: construction errors, project errors, different construction and repairs without checking structural safety and lack of control of construction and projects.

To prevent progressive collapse of buildings, lessons learned from the collapse of Zumrut Building are:

- In the structural design, the first rule will be life safety; the structure must first be safe under gravity loads, and then the design must consider lateral loads for life safety.

- In a building design, torsion is not a desired mode of dynamic behaviour of the building. International standards and codes consider the bending mode to be the preferred first mode; structural engineering design should prevent torsion from becoming the first mode.

- To prevent total collapse, the design of high-rise buildings must implement after studying the overall strength and stability of the 3-D structural system by assuming a local failure.

- To increase the structural performance of building structures, the use of indeterminate systems, 3-D behaviour, and 3-D continuous structural framing systems in both directions in the design will reduce the probability of progressive collapse and prevent the total failure of the building.
- Some architectural needs will reduce the overall torsional rigidity or discontinuity of structural systems or less redundant systems due to architectural reasons. In such cases, a new structural system or revised architectural system is required for safety.

- Locating floor areas in the console in some or all of the façade of a building is very common in Turkey to gain construction area above the ground level according to permissions in municipalities construction law. In such cases, frames do not properly transfer the forces under lateral loads or in cases of torsion due to a lack of beams between the columns. If these beams exist, they will probably pass through the rooms and corridors. For the structural continuity and transfer the forces alternative structural floor systems can be used, such as ribbed floors or flat-plate floor systems to integrate the architectural and structural system requirements. Otherwise, beams should be placed between the columns in the frame or the column lines should be put under console beams to construct a new frame at the exterior console part without closing the ground level from foundation to the top (not allowed in Turkey).

- If architectural changes done after construction of the building affect the structural system, whether through additional load or new load transferring, the structural system must be checked for structural safety.

\section{Conclusion}

In a local failure, redistribution of additional forces may exceed the capacity of neighbouring structural elements, causing local buckling or crushing of structural column elements. Local buckling or crushing may lead to local failure or even progressive collapse, as shown in the collapse of Zumrut Building. Therefore, a structure should be designed to provide capacity with continues structural systems allowed re-distribution of additional loading and stability. Selection of continuous 3-D structural system will prevent progressive collapse and primary collapse of the whole structural system due to redistribution of excess forces by creating a 3-D system of adequate strength and stability that accounts for the probability of local failures due to unexpected or accidental loads.

\section{References}

[1] C. Balkaya, "Collapsed reasons of Zumrut Building in Konya" (in Turkish). TMMOB Union of Chambers of Turkish Engineers and Architects, J. Teknik Guc, No: 135, 2004.

[2] C. Balkaya, "Investigation of collapsed Zumrut Building in Konya and progressive collapse mechanisms" 8th International Congress on Advances in Civil Engineering, Famagusta, North Cyprus, 2008.

[3] ETABSV8.11. "Structural and Earthquake Engineering Software" Computers and Structures, Inc. Berkeley. California, USA, 2002. 